\title{
Behaviours that Support Self-Understanding for People with Autism Spectrum Disorder in Vocational Rehabilitation
}

\author{
Kazuaki MAEBARA ${ }^{1}$ and Jun YAEDA ${ }^{2}$ \\ ${ }^{1}$ Department of Education and Human Studies, Akita University, Akita, Japan \\ ${ }^{2}$ Graduate School of Comprehensive Human Sciences, University of Tsukuba, Tokyo, Japan \\ maebarakazuaki@gmail.com
}

\begin{abstract}
This study identifies behaviours that support self-understanding for people with autism spectrum disorder (ASD) participating in vocational rehabilitation. The qualitative research (Study 1) used conceptual analysis to identify vocational rehabilitation practitioners' concept of support for self-understanding. The quantitative research (Study 2) surveyed 155 Japanese vocational rehabilitation practitioners using a questionnaire based on the results of Study 1. Exploratory factor analysis of the survey data determined the structure of behaviours that support self-understanding for people with ASD and found three behaviour types: 'Environmental setting of the current situation', 'Promoting awareness of the current situation', and 'Reflection based on collected information'. A practitioner was deemed to promote self-understanding support by using a combination of these three behaviours while heeding to the disabling characteristics of people with ASD. Identified support behaviours could be used as a fundamental perspective to develop a support programme to promote self-understanding for people with ASD.
\end{abstract}


Keywords: self-understanding support, vocational rehabilitation, mixed-method, concept analysis, autism spectrum disorder

In recent years, the number of jobs for disabled persons in Japan has increased (Ministry of Health, Labour and Welfare, 2020). There has been an increase in the number of cases involving people with autism spectrum disorder (ASD), and it is expected that support for people with ASD will further increase in the future. Meanwhile, the retention rate of autistic workers was $84.7 \%$ after the first three months of employment and $71.5 \%$ after the first year of employment (National Institute of Vocational Rehabilitation [NIVR], 2017a), indicating low levels of worker retention. Many people with ASD leave their workplaces due to the issues shown in the following examples, taken from the researcher's experience of vocational rehabilitation: 'I was unable to consult with my manager at work, I made a mistake, and so I stopped going to work without consulting anyone'; 'As supporters, we recognised that the client was an unsuitable match for their work duties, but the client stubbornly asserted, "I can work, I can do anything"'; and 'There is a disparity in awareness regarding the issues arising between workplace supervisors and clients'. From the perspective of practitioners requiring a smooth progression of support, there is a need for support that promotes self-understanding for people with ASD in order to resolve issues such as these. The NIVR (2017b) conducted a survey of Japanese vocational rehabilitation organisations and reported that there are seven key employment issues for people with 
ASD: self-understanding, communication, stress management, system use, work motivation, work environment adjustments, and lifestyle aspects. Most institutions recognise that of these aspects, the issues stem largely from the degree of self-understanding exhibited by individuals with ASD.

\section{Support for Self-Understanding}

Promoting client self-understanding is the foundation of vocational rehabilitation. Salomone (1996) divided the rehabilitation counselling process into five stages: (1) self-understanding (e.g. self-identification and related themes), (2) understanding of the occupational world and other relevant environments, (3) understanding of the decision-making process, (4) understanding of career and educated decisions, and (5) adaptation to the world of work and education. According to Rubin et al. (2016), 'Rehabilitation counselors' effectiveness in planning can be enhanced through the use of concrete procedures designed to facilitate client self-understanding. These procedures should be directed at helping people clarify both potential vocational goals and relationship of personal strengths and limitations to those vocational alternatives' (Rubin et al. 2016, p.320). Navin and Myers (1983) presented a self-understanding-focused support model based on the career development theory and reported the importance of the perspective of promoting self-understanding support in the practice of vocational rehabilitation. Moreover, it has been recognised that supporting self-understanding leads to client empowerment (Breeding, 2008) and changes in daily life (Haugli et al. 2011).

In Japan, self-understanding is considered an important concept, and the usefulness 
of its support has been noted in terms of the contribution to smooth support progression and elimination of client maladjustment (Japan Society for Vocational Rehabilitation, 2002), respect for client independence (Yamada, 2018), and promotion of self-determination (Japan Society for Vocational Rehabilitation, 2002). Confirming the support status of client self-understanding is particularly useful in formulating a work-transition support plan for people with ASD (Shibata, 2014). Furthermore, there are many case studies that focus on support for self-understanding, such as those that promote self-understanding through the experience of setbacks (Amano et al. 2016) as well as internships that have led to the promotion of self-understanding (Sato et al. 2019).

\section{Purpose of the Research}

As mentioned above, support for self-understanding for people with ASD is an important concept in vocational rehabilitation. Although the importance of self-understanding has been noted, most studies have not highlighted the importance and necessity of supporting it. Therefore, tactics and perspectives have not been suitably elucidated in the clinical framework of providing self-understanding support in vocational rehabilitation practice. Clarification of the clinical is essential to promote the implementation of self-understanding support in vocational rehabilitation practice for people with ASD in future. Moreover, the existence of this framework will be useful for vocational rehabilitation practitioners. Thus, the purpose of this study is to clarify support for self-understanding in vocational rehabilitation for people with ASD and identify support behaviours that will be useful for practical implementation. The research questions are as 
follows:

Research Question 1: What is the concept of self-understanding support provided by Japanese vocational rehabilitation practitioners?

Research Question 2: What self-understanding support behaviours are performed by Japanese vocational rehabilitation practitioners for clients with ASD?

\section{Method}

\section{Research Design}

This study implemented a mixed-method of exploratory sequential design using qualitative and quantitative methods. First, qualitative analysis was conducted on passages related to self-understanding support described in the case studies of professional rehabilitation practitioners. Following the creation of a survey using the results of the earlier qualitative analysis, this study then surveyed the vocational rehabilitation practitioners and analysed the results quantitatively.

\section{(A) Qualitative Research}

\section{Data collection}

This study utilised Japanese vocational rehabilitation practitioner case studies (551 cases) presented during the Japan Organisation for the Employment of the Elderly, Persons with Disabilities, and Job Seekers, hosted by the National Conference of Vocational Rehabilitation Research and Practice proceedings from 2011-2015. All case studies that mentioned the term 'self-understanding' at least once during the proceedings were regarded 
as research materials, regardless of disability (32 cases).

\section{Data analysis}

Current analysis uses concept analysis (Rodgers, 2000) to capture the power dynamics of the concept of self-understanding support from vocational rehabilitation practitioners. The purpose of the concept analysis was to collect and analyse around $20 \%$, or at least 30 papers, as a sample, and all the applicable literature was taken as the population.

The specific procedure was to determine a sample of literature and then conduct analysis from the following three perspectives of antecedents: (1) requirements that arise prior to the subject concept, (2) attributes of the subject concept in relation to predecessor requirements, and (3) consequences from the results of the subject concept. All three were derived from information from participants, interventions, research aims, and results. Related concepts were excluded from the analysis in this study.

\section{(B) Quantitative Research}

\section{Participants}

Participants were from Japanese vocational rehabilitation facilities who were vocational counsellors for disabled persons at 52 local vocational centres (including branches) and employees responsible for vocational support at 329 vocational and lifestyle support centres for disabled persons (as of 1 April, 2017).

All subjects gave their informed consent for inclusion before they participated in the study. The study was conducted in accordance with the Declaration of Helsinki, and the 
protocol was approved by the Ethics Committee.

\section{Data Collection Procedures}

The survey period was from 16 June, 2017 to 31 July, 2017. The survey was sent via email. Instead of aggregating opinions at each facility, the researchers asked all respondents to send their data digitally, receiving responses from those who agreed to participate in the research.

\section{Survey Items Listed in the Survey Table}

\section{Basic Attributes}

Age and years of experience in vocational support (as of April 1, 2017) were investigated as the basic attributes.

\section{Self-Understanding Support Behaviours}

(a) A total of 20 original items relating to self-understanding support behaviours were created based on the results of the attributes corresponding to the behaviours, obtained from the qualitative concept analysis results. The items were prepared in consultation with two researchers with experience in vocational rehabilitation (9 and 20 years, respectively) to increase the reliability and validity of the items. The items were created by asking, 'Based on your experience of supporting people with ASD, how frequently do you do the following (actively practice)?' Participants were asked to select the number that best described their performance frequency using a five-point Likert scale $(1=$ never, $2=$ not often, 3 = sometimes, 4 = often, 5 = always).

\section{Data Analysis}


Exploratory factor analysis of the answers was conducted to clarify self-understanding support behaviours. In addition, Pearson's correlation analysis between the subscale average score for each factor and the number of years of support was performed to determine the relationship between the performance of support behaviours and years of support experience.

\section{Results}

\section{(A) Study 1}

As shown in Figure 1, concept analysis allowed this study to organise the concept of self-understanding support.

\begin{tabular}{|c|c|c|}
\hline Antecedents & Attributes & Consequences \\
\hline - Difficulty in & - Reflecting on experiences & - Life changes \\
\hline understanding & - Feedback from others & - Behavioural \\
\hline disability & - Comprehension of the & changes \\
\hline - Lack of & current situation & - Preparation for \\
\hline \multirow[t]{5}{*}{ opportunities } & - Sorting the issues & employment \\
\hline & - Knowledge acquisition & - Application in \\
\hline & - Support tactics & employment support \\
\hline & & - Impact on stable \\
\hline & & work \\
\hline
\end{tabular}



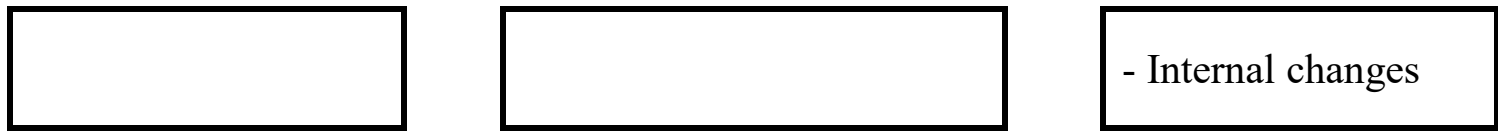

Figure 1. Results of conceptual analysis.

\section{Antecedents}

Vocational rehabilitation practitioners supported client self-understanding in the following circumstances. First, in situations where there is difficulty in understanding disability. This situation occurs when a client has 'Difficulty with accurately understanding their own disability' and 'Difficulty with understanding their disability, due to their disability'. Another situation is a 'Lack of opportunity', such as 'When the client has lived for a long time with non-disabled persons and has not had the opportunity to acquire necessary work skills'.

\section{Attributes}

Vocational rehabilitation practitioners performed the following actions as self-understanding support for clients.

Support behaviours for 'Reflecting on experiences' consisted of content relating to 'Understanding one's own characteristics through real-world experiences', 'Reflecting on the process, not the outcome', and 'Reflection and reappraisal of past experiences'.

Support behaviours for 'Feedback from others' consisted of content related to 'Strengths-based feedback', 'Specific advice in support situations', 'Reappraisal of characteristics based on others' opinions', and 'Insights from peers with the same 
disability'.

Support behaviours for 'Comprehending the current situation' consisted of content related to 'Comparison of past and present situation', 'Record of current status', 'Reflection implementation' and 'Skill check'.

Support behaviours for 'Issue sorting' consisted of content relating to 'Sorting one's own issues'.

'Knowledge acquisition' support behaviours consisted of content relating to 'Gaining necessary work knowledge, such as that of systems and businessmen'.

Support behaviours for 'Support tactics' consisted of content relating to 'Communication of the current situation in light of disability characteristics', 'Creation of an environment where failure is acceptable', 'Setting activity expectations', 'Timely feedback', 'Encouraging rather than aiming for change', 'Providing feedback via individual interviews', and 'Use of visuals, such as text and diagrams'.

\section{Consequences}

Vocational rehabilitation practitioners aimed to achieve the following via self-understanding support: 'Lifestyle changes' such as 'Life plan consideration' rather than continuation of employment; 'Behavioural changes' such as 'Good interpersonal relationships', 'Consultation with third parties', and 'Adaptive behaviour' in the workplace; 'Preparedness for work' such as 'Reduced work-related anxiety' of the client and 'Work-ready capacity'; 'Applicability to vocational support' such as 'Possibility of job-matching', Capacity for investigation work methods', 'Ability to comprehend one's 
own disability', and 'Gaining the knowledge necessary for work' in terms of the client's support; 'Impact on stable work' such as the client's 'Expectation of the possibility of long-term employment'; and 'Internal changes' such as the client 'Gaining confidence and self-respect' and the 'Ability to gain a sense of independence'.

\section{(B) Study 2}

\section{Recovery Rate}

At the final count, valid responses were received from 29 vocational counsellors for disabled persons and 126 work support managers. The recovery rate, calculated by dividing the number of institutions from which at least one response was received by the number of institutions that were sent questionnaires, was $55.8 \%$ for local work centres for disabled persons, $38.8 \%$ for work and lifestyle support centres for disabled persons, and $40.7 \%$ overall.

\section{Basic Attributes}

The basic attributes of the survey participants are shown in Table 1. 
Table 1

Basic Attributes

$\begin{array}{llll}\text { Organisation } & \text { M } & \text { SD } & \text { Range }\end{array}$

Total (155 individuals)

Age (years)

42.1

8.24

$25-63$

Years of support experience

9.2

7.59

$0-36$

Vocational counsellors for disabled persons (29

individuals)

6.55

32-59

Age

19.7

7.10

10-36

Support experience

Employment support personnel (126 individuals)

Age

41.2

8.58

25-63

Support experience

6.8

5.31

0-26

\section{Support Behaviour for People with ASD}

Exploratory factor analysis (least squares, promax rotation) was performed using the answers from 20 questionnaire items. The decay status of the eigenvalues was 7.891 , 1.776, 1.013, and 0.969, and a three-factor solution was adopted because of the Kaiser-Guttman criterion (eigenvalue $\geq 1.0$ ) and the possibility of factor interpretation. Table 2 shows the factor patterns resulting from the promax rotation. 
Table 2

Factor Patterns

\begin{tabular}{|c|c|c|c|c|}
\hline No. & Item & Factor 1 & Factor 2 & Factor 3 \\
\hline \multicolumn{5}{|c|}{ Factor 1: Environmental setting of the current situation $($ Cronbach's $\alpha$ coefficient $=.844)$} \\
\hline 16 & Ensure that the participant is aware of the support. & .856 & .039 & -.117 \\
\hline 15 & Provide a safe environment where one can feel secure, even in failure. & .822 & -.119 & .015 \\
\hline 20 & Supporters will make use of visuals (notes, diagrams, etc.) when discussing the current situation and issue organisation. & .704 & -.101 & .132 \\
\hline 14 & $\begin{array}{l}\text { Be mindful of the characteristics of a person's disability and how they comprehend information when communicating the curr } \\
\text { situation. }\end{array}$ & .620 & .120 & -.146 \\
\hline 17 & $\begin{array}{l}\text { When communicating about issues or results, do so immediately in specific situations when the issues arise or when results ha } \\
\text { been obtained. }\end{array}$ & .546 & .023 & .051 \\
\hline 18 & Rather than aiming to significantly alter client perceptions and behaviours at once, provide support which will help the client & .451 & .122 & .020 \\
\hline
\end{tabular}


achieve a series of small changes.

The supporter indicates the status of the work preparation (i.e. the presence or absence of vocational preparedness and work

11 skills).

Factor 2: Promoting recognition of the current state $($ Cronbach's $\alpha$ coefficient $=.825)$

2 Instead of focusing only on the results, focus on the details of the process that leads to the results.

During consultation, review difficulties that arose during employment experiences thus far to enable the client to understand their

own issues.

4 As a supporter, communicate the client's strengths and positive attributes, not just their weaknesses and challenges.

1 Have clients attempt various types of work training and provide opportunities for work experience in a range of different settings.

Factor 3: Reflection based on collected information (Cronbach's $\alpha$ coefficient $=.819)$

13 Set up training to gain the knowledge necessary for work to get the client to think about working. 
7 Set up a group work setting to provide an opportunity to exchange opinions with others.

$-.112$

$-.013$

.063

19 Provide regular opportunities for individual consultation.
Factor 1

Factor 2

Factor 3
1.000

.759

1.000
.544

\begin{tabular}{|c|c|c|c|}
\hline Factor 2 & .759 & 1.000 & \\
\hline Factor 3 & .641 & .597 & 1.000 \\
\hline
\end{tabular}


Cronbach's $\alpha$-coefficients for each of the three factors was $.844, .825$, and .819 , respectively.

\section{Relationship Between Support Actions and Years of Support}

The performance frequency of each factor was scored and the average value of each item was calculated (Table 3).

Table 3

Factor Performance Scores

\begin{tabular}{llll}
\hline Factor & $\mathrm{M}$ & $\mathrm{SD}$ & Range \\
\hline F1 & 3.98 & 0.05 & $2.14-5.00$ \\
F2 & 4.10 & 0.05 & $2.00-5.00$ \\
F3 & 3.19 & 0.05 & $1.63-5.00$ \\
\hline
\end{tabular}

Pearson's correlation analysis was performed between the factor performance scores and the number of years of support experience. The results showed significant correlations between all factors (Factor $1: \mathrm{R}=.234, \mathrm{p}<.01$; Factor $2: \mathrm{R}=.195, \mathrm{p}<.05$; Factor $3: \mathrm{R}=.315, \mathrm{p}<.01)$.

\section{Discussion}


The characteristics of self-understanding support behaviours for people with ASD include actions such as setting up an environment to understand their current situation (i.e. their disability and their position in society) and facilitating opportunities for proactive information gathering. Vocational rehabilitation practitioners are believed to deliver a combination of these support actions to promote self-understanding for people with ASD. In a supplemental interview survey of vocational rehabilitation practitioners, this study was able to access practitioners' perspectives on implementing a combination of these support actions. One practitioner said:

It is difficult to gain a deep understanding of the reasons for a person with ASD to dislike or avoid behaviours, such as when they say they do not like their workplace so they do not want to work there, or they think it is best to avoid it rather than attempt to get along with the people that they do not like. As a result, it tends to be difficult to link this to adaptive environmental adjustments and response method training. The support of people with ASD is therefore designed to progress from recognising such weaknesses and examining specific adaptation measures, such as how to communicate such difficulties to a company.

As outlined in the practitioner's comment, the disability profile of people with ASD includes characteristics that impede the promotion of self-understanding in the first place. For example, it has been highlighted that people with ASD have the following triad of impairments: deficits in social relations, communication, and imagination (Wing, 1996). Moreover, as Gaus (2007) pointed out, clients have information processing system issues 
such as theory of mind, language comprehension, understanding social cues, planning and goal setting, and emotional regulation. As a result, clients with ASD experience difficulty in implementing the abstract meta-cognitive thinking process of self-understanding. For example, there is insufficient self-understanding for them to help themselves become established in the workplace, such as the impact of their said weakness on the workplace and whether there is an actual need to request company assistance to deal with it. Therefore, to support self-understanding for people with ASD, it is necessary to not only organise the current situation but to also consider effective measures for workplace adaptation. In this way, self-understanding support for people with ASD aims to encourage a more practical self-understanding of workplace adaptation.

\section{Factors Influencing the Delivery of Self-Understanding Support}

A significant correlation was found between the delivery of self-understanding support and the number of years of support experience. Vocational rehabilitation practitioners' knowledge and skills of supporting people with ASD, obtained through their support experience, may influence the delivery of self-understanding support behaviours for people with ASD. Mochizuki (2010) highlighted the importance of characteristic-based evaluation and support due to the diversity of presentations and the highly individual nature of disability in ASD. Furthermore, Otani (2012) pointed out that supporters with less experience of supporting people with ASD tend to assume that a lack of understanding on the part of the person with ASD is the reason for the difficulty of providing support. In Japan, the number of support cases for people with ASD has increased in recent years. As a 
result, practitioners lack the knowledge and skills to support people with ASD compared to those with intellectual disabilities, as they have a great deal of experience in managing support for people with intellectual disabilities. Moreover, few professions are involved in vocational rehabilitation, so there is limited accumulation of support know-how. Thus, given this background, it is thought that the impact of years of support experience is likely to explain the experience of supporting people with ASD and the possession of vocational rehabilitation knowledge and skill.

\section{Implication for Stakeholders}

In Japan, the support needs of people with ASD have increased in recent years, not only in the field of vocational rehabilitation but also in terms of transition support, from higher education to work and return to work support for clients who have been absent due to ASD-related secondary disabilities. Therefore, the development of a support programme for ASD participants is required to respond to these needs. In particular, support for self-understanding is considered to be a fundamental support concept in the delivery of vocational interventions, and is expected to serve as a viewpoint for developing support programmes to promote the self-understanding of people with ASD.

In the past, support for self-understanding has been primarily based on a subjective approach to an abstract concept of the self. Therefore, there have been situations in which approaches were undertaken that diverged from those of rehabilitation counselling, such as practitioners expecting the client to unilaterally promote self-understanding. The results of the current study are expected to be potentially useful as a guide for individual practitioners 
conducting self-understanding support.

\section{Limitations of the Study}

This study organised vocational rehabilitation practitioners' support for self-understanding at the behavioural level. Although the relationship with years of support experience was investigated, no other factors contributing to the implementation of self-understanding support were identified. When considering the development of support programmes and practitioners, it is important to identify the factors that contribute to the implementation of self-understanding support. In addition to the years of support experience, it may be necessary to investigate the impact of factors such as the level of vocational rehabilitation knowledge and skills and the status of co-operation with relevant organisations on the implementation of self-understanding support.

\section{Recommendations for Further Research}

This study sought to identify vocational practitioners' self-understanding of support behaviours regarding people with ASD. The following two aspects are expected in future research. First, the effectiveness of self-understanding support behaviours will be validated. In this regard, it is necessary to test the effectiveness of self-understanding support through the development and stimulation of programmes that promote self-understanding based on support behaviours. The second is the validation of the qualitative meaning of whether self-understanding support delivered by practitioners is truly meaningful to clients with ASD. This will lead to a more detailed decision-making process for practitioners, such as the optimum circumstances and timing for delivery of self-understanding support, which 
will need to be investigated in the future.

\section{References}

Amano, N., Shiouchi, M., \& Kataoka, Y. (2016.) What is a good quality student service for students with developmental disorders? Chubu Gakuin University and Chubu Gakuin College Journal of Educational Research and Practice, 1, 171-179.

Breeding, R. R. (2008). Empowerment as a function of contextual self-understanding: The effect of work interest profiling on career decision self-efficacy and work locus of control. Rehabilitation Counseling Bulletin, 51(2), 96-106.

https://doi.org/10.1177/0034355207311346

Gaus, V. L. (2007). Cognitive-behavioral therapy for adult Asperger syndrome. New York: Guilford Press.

Haugli, L., Maeland, S., \& Magnussen, L. H. (2011). What facilitates return to work? Patients experiences 3 years after occupational rehabilitation. Journal of Occupational Rehabilitation, 21(4), 573-581.

Japan Society of Vocational Rehabilitation. (2002). Vocational Rehabilitation Glossary (2nd Ed.) (translated from Japanese). Japan Society of Vocational Rehabilitation.

Matsui, N. (2013). Considerations in the promoting of the supporter's talent for the employment of persons with disabilities (translated from Japanese). The Japanese Journal of Labour Studies, 55(10), 54-62.

Ministry of Health, Labor and Welfare. (2020). Employment placement status for persons 
with disabilities, etc. (translated from Japanese).

https://www.mhlw.go.jp/content/11704000/000641906.pdf

Mochizuki, Y. (2010). Challenges for employment support for university students with developmental disabilities for a smooth transition to profession and selection of appropriate support (translated from Japanese). University and Students, 81(6), 2228.

National Institute of Vocational Rehabilitation. (2017a). Research on employment status of persons with disabilities (translated from Japanese). (Research Report No. 137). National Institute of Vocational Rehabilitation.

https://www.nivr.jeed.go.jp/research/report/houkoku/houkoku137.html

National Institute of Vocational Rehabilitation (2017b). Research study concerning current situations of the regional employment support network for persons with developmental disabilities-ten years after the enforcement of the Act on Support for Persons with Developmental Disabilities (translated from Japanese). (Research Report No. 135). National Institute of Vocational Rehabilitation. https://www.nivr.jeed.go.jp/research/report/houkoku/houkoku135.html

Navin, S. L., \& Myers, J. E. (1983). A model of career development for disabled adults. Journal of Applied Rehabilitation Counseling, 14(2), 38-43.

\section{https://doi.org/10.1891/0047-2220.14.2.38}

Otani, H. (2012). Transition support for employment of people with developmental disabilities in relation to their self-understanding of their work life: Multivariate 
analysis of data from employment assistance providers (translated from Japanese). Japanese Journal of Special Education, 50(1), 13-20. https://doi.org/10.6033/tokkyou.50.13

Rodgers, B. L., \& Knafl, K. A. (2000). Concept development in nursing: Foundations, techniques, and applications (2nd ed.). Philadelphia: W. B. Saunders Company.

Rubin, S. E., Roessler, R. T., \& Rumrill Jr, P. D. (2016). Foundations of the vocational rehabilitation process (7th ed.). Texas: Pro-ed.

Salomone, P. R. (1996). Career counselling and job placement: Theory and practice. In E. M. Szymanski, \& R. M. Parker (Eds.), Work and disability issues and strategies in career development and job placement (pp. 365-420). Texas: Pro-ed.

Sato, M., \& Kudo, Y. (2019). Self-decision support utilizing employment experience for autism spectrum disorder in university student: Through comparing internship and part-time job (translated from Japanese). Meisei Daigaku Hattatsu Shien Kenkyu Senta Kiyo: MISSION, 4, 95-111.

Shibata, Y. (2014). The presence of merkmark when unsure of how to support (translated from Japanese). Japanese Journal of Vocational Rehabilitation, 28(1), 21-25.

Wing, L. (1996). The autistic spectrum a guide for parents and professionals. London: Constable and Company Ltd.

Yamada, J. (1995). A program to help self-understanding of people with mild mental retardation (translated from Japanese). Japanese Journal of Vocational Rehabilitation, 8, 1-7. 